\title{
The efficacy and safety of nutritional supplement use in a representative sample of adults in the North/South Ireland Food Consumption Survey
}

\author{
M Kiely ${ }^{1, *}$, A Flynn ${ }^{1}$, KE Harrington ${ }^{2}$, PJ Robson ${ }^{3}, \mathrm{~N} \mathrm{O}^{\prime}$ Connor ${ }^{1}$, EM Hannon', \\ MM O'Brien ', S Bell ${ }^{3}$ and JJ Strain ${ }^{3}$ \\ Irish Universities Nutrition Alliance (IUNA) at: 'Nutritional Sciences, Department of Food Science, \\ Food Technology and Nutrition, University College, Cork, Republic of Ireland: ${ }^{2}$ Department of Clinical Medicine, \\ Trinity Centre for Health Sciences, St. James's Hospital, Dublin 8, Republic of Ireland: ${ }^{3}$ Northern Ireland Centre for \\ Diet and Health (NICHE), University of Ulster, Coleraine, Co. Londonderry, BT52 1SA, Northern Ireland
}

\begin{abstract}
Objective: To describe the current use of nutritional supplements and their contribution to micronutrient intakes in a representative sample of Irish adults, to evaluate the impact of supplement use on the adequacy of micronutrient intakes and to assess the risk to supplement users of exceeding tolerable upper intake levels (UL).

Study design and subjects: Food intake data were collected in 1379 (662 male and 717 female) randomly selected Irish adults aged 18 to 64 years using a 7-day food diary. The current use of nutritional supplements was assessed using a selfadministered questionnaire and respondents entered each supplement as it was consumed into the food diary.

Results: Twenty-three per cent of respondents regularly used nutritional supplements. Twice as many women used supplements as men. The intakes of micronutrients were significantly higher $(P<0.001)$ in supplement users than in non-users. Micronutrient intakes from food sources were similar in male users and non-users of supplements, but were significantly higher $(P<0.01)$ in female users, by 3 to $13 \%$, for $\mathrm{Fe}, \mathrm{Mg}, \mathrm{Mn}$, vitamins $\mathrm{C}$ and $\mathrm{E}$ and niacin than in non-users. The percentage of female users between 18 and 50 years who had mean Fe intakes below the average requirement (AR) $(10 \mathrm{mg})$ decreased from 50 to 25 when the contribution from supplements was included. The use of supplements reduced the percentage of men who had mean intakes below the AR for $\mathrm{Zn}$ from 19 to 13 , for riboflavin from 14 to 6 and for vitamin A from 20 to 5 , and reduced the percentage of women with intakes below the AR for $\mathrm{Ca}$ from 23 to 16 and for riboflavin from 23 to 14. Twenty-one women out of 80 aged between 18 and 50 years, who consumed supplemental folate, achieved the intake of $600 \mu \mathrm{g}$ recommended to prevent neural tube defects. Twenty-two per cent of the women who took iron and $15 \%$ of the women who took vitamin $\mathrm{B}_{6}$ in supplemental form had mean daily intakes that exceeded that UL for these nutrients. Supplement users did not exceed the UL for the other micronutrients.

Conclusions: Supplementation appears to be beneficial in promoting adequate intakes of some micronutrients, particularly $\mathrm{Fe}$ and folate in women aged 18-50 years and vitamin A in men. There appears to be little risk to supplement users of experiencing adverse side effects due to excessive intakes of micronutrients.
\end{abstract}

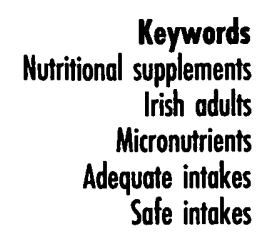

Nutritional supplements constitute a sector of the dietary supplement market that is growing fast in all countries of the developed world ${ }^{1}$. In the USA, nutritional supplements have become the hottest item in the nutrition-related marketplace ${ }^{2}$. In this rapidly expanding market, vitamins and minerals constituted $51 \%$ of sales in 1997 , with herbal products and botanicals (the fastest-growing sector) amounting to $33 \%^{2}$. A recent 
evaluation of preliminary data from the European Prospective Investigation into Cancer (EPIC) study in the UK has indicated that the contribution from dietary supplements to nutrient intakes can be substantial, which suggests that gross misclassification of nutrient intakes can occur if supplements are not accounted for ${ }^{3}$.

The motivating factors that encourage supplement use and the lifestyle characteristics of supplement users have been investigated ${ }^{4}$. Kirk et $a l^{4}{ }^{4}$ showed that users were more likely to be vegetarian, vegan or fish consumers, to eat more fruit and vegetables, be more physically active and have a lower alcohol intake than non-users. However, the efficacy and safety of supplement consumption have not been evaluated sufficiently in representative population groups. There is a need for unbiased, peerreviewed evaluations that assess the scientific evidence as to the efficacy and safety of dietary supplements ${ }^{2}$. Efficacy can be defined as the ability of a supplement to provide a health benefit related to either the prevention of a nutritional deficiency or reduction in the risk of disease, while safety denotes a reasonable certainty that there will be no adverse effects from excessive intake of a nutrient ${ }^{5}$. To date, there is very little information available on supplement use in Ireland. The North/South Ireland Food Consumption Survey has established a database of habitual food consumption in a representative sample of the Irish population aged 18 to 64 years. The use of dietary supplements in this population was assessed concurrently.

The aims of this report are to describe the current use of nutritional supplements in Irish adults and their contribution to micronutrient intakes, to assess the impact of supplement use on adequacy of micronutrient intakes and to evaluate the risk to supplement users of exceeding tolerable upper intake levels (UL).

\section{Methods}

The methods used in the North/South Ireland Food Consumption Survey are comprehensively described elsewhere ${ }^{6,7}$. Briefly, food intake was measured in 1379 randomly selected adults aged 18-64 years using a 7-day estimated food diary. Additional information was collected from respondents using self-administered questionnaires, including socio-demographic data, habitual physical activity levels, attitudes, eating behaviours and health status. The food consumption data were processed using WISP ${ }^{\circledR}$ (Tinuviel Software, Warrington, UK), which uses McCance \& Widdowson's The Composition of Foods, fifth edition ${ }^{8}$ plus supplemental volumes ${ }^{9-17}$ to generate nutrient intake data. The nutrient database was expanded to include generic Irish foods and new products that were commonly consumed. The data handling and data processing procedures used in the current study are described fully in an accompanying paper ${ }^{6}$.

\section{Assessment of supplement consumption}

Current supplement use was assessed by respondents' answer to the question 'Do you take any vitamins, minerals or other food supplements currently?', which was included in the self-administered health and lifestyle questionnaire. Respondents also entered each supplement as it was consumed into the 7-day food diary. Researchers checked that respondents who had reported using supplements in the questionnaire, which was administered at the start of the recording week, entered the supplements into the food diary when they were consumed. In the respondent's home, the researcher transcribed the nutrient composition of each supplement from the product label. This method has been referred to as a 'gold standard' for the assessment of supplement use $^{18}$. The data were checked centrally and added to the nutrient composition database. Each nutrient-containing supplement was assigned a new food code. Researchers entered supplements into the food consumption database in the same way as they entered foods from the 7-day diaries. In this way, supplement consumption was measured alongside food consumption.

\section{Statistical analysis}

The food consumption database was analysed using SPSS $^{\circledR}$ for Windows ${ }^{\mathrm{TM}}$ Version 8.0 (SPSS Inc., Chicago, IL). Mean micronutrient intakes from food sources and supplements were compared with estimated average requirements (ARs) ${ }^{19}$. In addition, median values were reported and mean nutrient intakes at the 95th percentile were compared with tolerable upper intake levels (ULs) $^{20-28}$. Differences between mean micronutrient intakes in men and women and between supplement users and non-users were tested using independent $t$-tests and Mann-Whitney $U$-tests ( $99 \%$ confidence interval (CI)) depending on whether the data were normally distributed or not. Differences in micronutrient intakes between supplement users before and after the inclusion of supplements were tested separately for men and women using repeated measures $t$-tests $(99 \% \mathrm{CI})$. Owing to the large sample size, even a small difference between group means was highly statistically significant, so this paper focuses more on a descriptive analysis of the impact of supplement use on micronutrient intakes in users than on the statistical differences in group means between users and non-users.

\section{Results}

A description of the types of supplement consumed by supplement users in the current study is given in Table 1. Almost $27 \%$ of the total number of supplements used by respondents were single-vitamin preparations. Cod liver oil preparations retain their popularity despite the expanding variety of supplements available and 19 different products based on cod liver oil were used. 
Table 1 Description of nutritional and non-nutritional supplements used by the population surveyed $(n=1379)$ during 7 days in the North/South Ireland Food Consumption Survey

\begin{tabular}{lcc}
\hline Supplements & Number & \% of total \\
\hline Vitamins & 49 & 26.6 \\
Vitamin C & 17 & 9.2 \\
B/B complex & 15 & 8.2 \\
Vitamin E & 9 & 4.9 \\
Multivitamins & 5 & 2.7 \\
Folic acid & 2 & 1.1 \\
B-Carotene & 1 & 0.5 \\
Minerals & 27 & 14.7 \\
Iron & 13 & 7.1 \\
Calcium & 9 & 4.9 \\
Zinc & 3 & 1.6 \\
Magnesium & 1 & 0.5 \\
Selenium & 1 & 0.5 \\
Multivitamins \& minerals & 30 & 16.3 \\
Fish oil/Cod liver oil & 19 & 10.3 \\
Primrose/Starflower oil & 17 & 9.2 \\
Protein powders & 4 & 2.2 \\
Slimming powders & 1 & 0.5 \\
Non-nutritional supplements* & 37 & 20.1 \\
Total & 184 & 100 \\
\hline
\end{tabular}

* Includes ginseng, garlic capsules, aloe vera juice, biodopholous and others that were not entered into the compositional database as they did not contain nutrients.

Non-nutritional supplements, e.g. garlic, ginseng and aloe vera juice, were also widely used and accounted for $20 \%$ of the 184 supplements recorded.

Table 2 shows that, according to the questionnaire, a total of 387 respondents (28\%) said that they were currently using supplements, while 323 (23\%) consumed supplements during the recording week. A total of $83.5 \%$ of the respondents who reported currently using supplements consumed them at least once during the subsequent week. Twice as many women used supplements as men and this ratio did not change with age.

Table 2 Comparison of supplement use by age and sex in respondents who reported currently taking supplements in a questionnaire and in respondents who recorded them in the 7day food diary during the North/South Ireland Food Consumption Survey

\begin{tabular}{lrrrrr}
\hline & \multicolumn{2}{c}{ Questionnaire } & & \multicolumn{2}{c}{ Food diary } \\
\cline { 2 - 3 } \cline { 5 - 6 } Population group & $n$ & $\%$ & & $n$ & $\%$ \\
\hline 18-64 years & & & & \\
All & 387 & 28 & & 323 & 23 \\
Men & 127 & 19 & & 103 & 16 \\
Women & 260 & 36 & & 220 & 31 \\
18-35 years & & & & \\
All & 124 & 24 & & 111 & 21 \\
Men & 42 & 17 & & 37 & 15 \\
Women & 82 & 30 & & 74 & 28 \\
36-50 years & & & & \\
All & 162 & 31 & & 134 & 26 \\
Men & 47 & 20 & & 41 & 17 \\
Women & 115 & 40 & & 93 & 33 \\
51-64 years & & & & \\
All & 101 & 30 & 78 & 23 \\
Men & 38 & 22 & 25 & 14 \\
Women & 63 & 39 & 53 & 33 \\
\hline
\end{tabular}

People in the 36-50 and 51-64 year age categories had a slightly higher rate of supplement use than the 18-35 year olds.

Table 3 shows the median intakes of six minerals and 11 vitamins in male and female users and non-users of supplements, and the percentage of each group that had mean daily intakes below the estimated average requirements $(\mathrm{AR})^{19}$. The nutrient intakes of supplement users are presented from food sources plus supplements and from food sources only. Mean daily micronutrient intakes were significantly higher $(P<0.01)$ in men than in women, with the exception of iron and vitamin $\mathrm{E}$ in supplement users and carotene in users and non-users. In men and women, the mean daily intakes of micronutrients were significantly higher $(P<0.001)$ in users than in non-users when the contribution from supplements was included. In users, mean daily nutrient intakes from food sources only were significantly lower in men $(P<0.01)$ and women $(P<0.0001)$ than intakes from food sources plus supplements. In women, the mean daily intakes of iron, magnesium, manganese, vitamins $\mathrm{C}$ and $\mathrm{E}$ and niacin in users from food sources only were significantly higher $(P<0.01)$, by 3 to $12 \%$, than in non-users.

Relatively small percentages of men (users and nonusers) had mean nutrient intakes from food sources only that were below the $\mathrm{AR}$, except for calcium, zinc, riboflavin and vitamin $A$. The inclusion of supplements in male users reduced the percentage below the AR for zinc from 19 to 13 , for riboflavin from 14 to 6 and for vitamin A from 20 to 5 , but had no effect on the adequacy of calcium intakes. In general, higher percentages of women had mean nutrient intakes from food sources below the AR than men, especially for calcium, iron, copper, folate and riboflavin. In women, the percentages of non-users who had mean nutrient intakes below the AR were larger than the percentages of users for calcium, iron, copper, vitamin $\mathrm{C}$ and folate. Over a quarter of female non-users had mean intakes of calcium and copper that were below the AR. Over half of female non-users aged 18 to 50 years had mean intakes of iron that were below the $\mathrm{AR}$. In users, the addition of supplements reduced the percentage below the AR for calcium from 23 to 16 , for iron from 50 to 25 (18-50 years), for copper from 20 to 15 , for zinc from 15 to 12 , for riboflavin from 23 to 14 , and for vitamin A from 18 to 14 .

Tables $4 \mathrm{a}$ and $4 \mathrm{~b}$ show the mean micronutrient intakes in male and female users from supplements and food sources. Values were calculated per nutrient based on the number of users who consumed that nutrient in supplemental form. Vitamin $\mathrm{E}$ was the nutrient most frequently obtained from supplements in male (78\%) and female (73\%) users. In men, supplements contributed more to the mean intakes of thiamin, riboflavin, retinol and vitamins $E, D$ and $C$ than food did. In addition, over one-third of the mean intakes of iron, copper, zinc, folate 


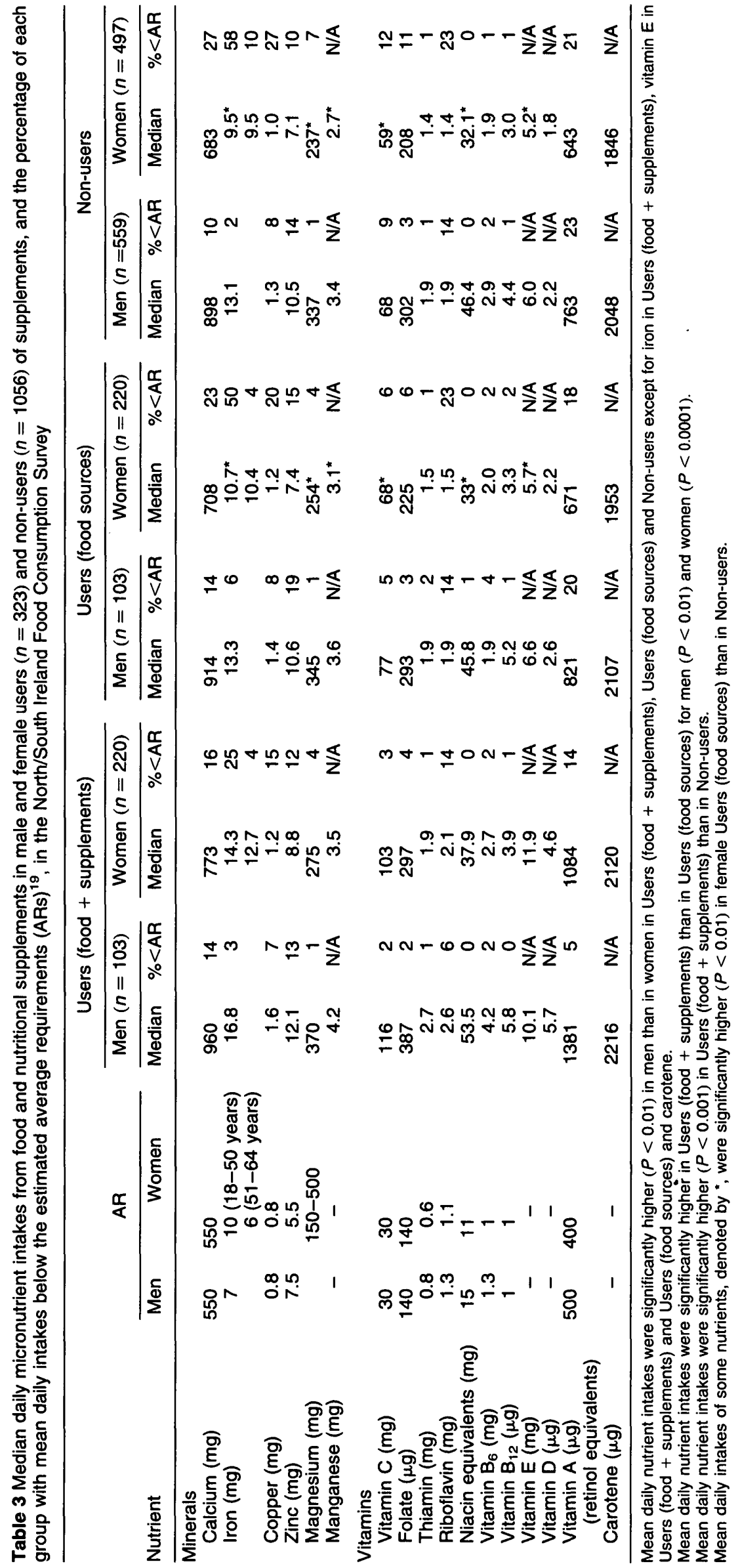


Table 4 Micronutrient intakes from nutritional supplements and food sources in men and women who took supplements during the North/ South Ireland Food Consumption Survey

\begin{tabular}{|c|c|c|c|c|c|c|c|c|c|c|c|}
\hline \multirow[b]{2}{*}{ Nutrient } & \multicolumn{2}{|c|}{ Consumers } & \multicolumn{3}{|c|}{ Nutritional supplements } & \multicolumn{3}{|c|}{ Food sources } & \multicolumn{3}{|c|}{ Total } \\
\hline & $n$ & $\%$ & Mean & SD & Median & Mean & SD & Median & Mean & SD & Median \\
\hline \multicolumn{12}{|l|}{$\begin{array}{l}\text { (a) Men }(n=103) \\
\text { Minerals }\end{array}$} \\
\hline Calcium (mg) & 39 & 38 & 98 & 82 & 82 & 911 & 332 & 884 & 1009 & 355 & 1005 \\
\hline Iron (mg) & 44 & 43 & 9.5 & 5 & 10 & 13.2 & 4 & 13.4 & 22.6 & 7 & 22.4 \\
\hline Copper (mg) & 35 & 34 & 0.9 & 1 & 0.6 & 1.6 & 1 & 1.4 & 2.5 & 1 & 2.4 \\
\hline Zinc (mg) & 39 & 38 & 8.1 & 6 & 5 & 10.3 & 3 & 10.6 & 18.4 & 7 & 17.9 \\
\hline Magnesium (mg) & 25 & 24 & 75 & 81 & 86 & 357 & 101 & 351 & 432 & 112 & 449 \\
\hline Manganese (mg) & 22 & 21 & 1.7 & 1 & 1.4 & 3.8 & 1.6 & 3.6 & 5.5 & 2 & 5.5 \\
\hline \multicolumn{12}{|l|}{ Vitamins } \\
\hline Vitamin C (mg) & 68 & 66 & 343 & 596 & 60 & 85 & 46 & 74 & 427 & 598 & 169 \\
\hline Folate $(\mu \mathrm{g})$ & 46 & 45 & 199 & 113 & 200 & 307 & 131 & 286 & 506 & 154 & 495 \\
\hline Thiamin (mg) & 50 & 49 & 2.6 & 4 & 1.4 & 2.2 & 2 & 2.0 & 4.8 & 4 & 3.5 \\
\hline Riboflavin (mg) & 49 & 48 & 2.4 & 4 & 1.6 & 2.1 & 1 & 2.0 & 4.5 & 4 & 3.8 \\
\hline Niacin equivalents (mg) & 51 & 50 & 13.6 & 10 & 12.9 & 46.9 & 13 & 44.7 & 60.4 & 15 & 59.4 \\
\hline Vitamin $B_{6}(\mathrm{mg})$ & 51 & 50 & 3.8 & 4 & 2 & 2.9 & 1 & 2.9 & 6.8 & 5 & 5.4 \\
\hline Vitamin $B_{12}(\mu \mathrm{g})$ & 48 & 47 & 2.9 & 5 & 1.3 & 5.2 & 4 & 4.3 & 8.1 & 6 & 6.7 \\
\hline Vitamin E (mg) & 80 & 78 & 37.5 & 102 & 7.4 & 7 & 3 & 6.9 & 44.5 & 101 & 14.8 \\
\hline Vitamin $D(\mu \mathrm{g})$ & 74 & 72 & 4.2 & 3 & 2.8 & 3.2 & 3 & 2.4 & 7.4 & 4 & 6.5 \\
\hline Retinol $(\mu \mathrm{g})$ & 76 & 74 & 692 & 290 & 760 & 646 & 891 & 413 & 1338 & 909 & 1188 \\
\hline Carotene $(\mu \mathrm{g})$ & 17 & 17 & 412 & 534 & 200 & 2230 & 1283 & 1913 & 2643 & 1194 & 2471 \\
\hline \multicolumn{12}{|l|}{$\begin{array}{l}\text { (b) Women ( } n=220 \text { ) } \\
\text { Minerals }\end{array}$} \\
\hline Calcium (mg) & 79 & 36 & 240 & 380 & 162 & 778 & 328 & 681 & 1017 & 486 & 911 \\
\hline Iron (mg) & 96 & 44 & 29.8 & 42 & 13.8 & 10.5 & 4 & 9.8 & 40.4 & 42 & 22.7 \\
\hline Copper (mg) & 60 & 27 & 1.1 & 1 & 0.9 & 1.1 & 1 & 0.9 & 2.3 & 1 & 2.1 \\
\hline Zinc (mg) & 68 & 31 & 9.9 & 10 & 9.3 & 7.7 & 3 & 7.1 & 17.6 & 11 & 18.2 \\
\hline Magnesium (mg) & 59 & 27 & 93 & 61 & 100 & 272 & 103 & 251 & 364 & 125 & 335 \\
\hline Manganese (mg) & 55 & 25 & 2.4 & 2 & 2 & 3 & 0.9 & 2.9 & 5.4 & 2 & 4.9 \\
\hline \multicolumn{12}{|l|}{ Vitamins } \\
\hline Vitamin C (mg) & 113 & 51 & 231 & 390 & 60 & 83 & 48 & 72 & 315 & 393 & 153 \\
\hline Folate $(\mu \mathrm{g})$ & 96 & 44 & 258 & 212 & 200 & 235 & 74 & 231 & 493 & 231 & 433 \\
\hline Thiamin (mg) & 98 & 45 & 4.8 & 10 & 1.4 & 1.5 & 0.8 & 1.4 & 6.3 & 10 & 2.9 \\
\hline Riboflavin (mg) & 96 & 44 & 3.9 & 8 & 1.6 & 1.6 & 0.6 & 1.5 & 5.5 & 8 & 3.2 \\
\hline Niacin equivalents $(\mathrm{mg})$ & 94 & 43 & 16.3 & 14 & 15.6 & 34.5 & 10 & 33.4 & 50.7 & 19 & 47.4 \\
\hline Vitamin $B_{6}(\mathrm{mg})$ & 94 & 43 & 9.3 & 15 & 2 & 2.1 & 0.7 & 2 & 11.4 & 15 & 4.2 \\
\hline Vitamin $B_{12}(\mu \mathrm{g})$ & 92 & 42 & 3.6 & 6 & 1 & 3.9 & 3 & 3.2 & 7.5 & 7 & 4.9 \\
\hline Vitamin E (mg) & 160 & 73 & 23.1 & 53 & 10 & 6.4 & 3 & 5.8 & 29.4 & 54 & 15.3 \\
\hline Vitamin $D(\mu g)$ & 133 & 60 & 4.8 & 4 & 4.3 & 2.8 & 2 & 1.9 & 7.4 & 5 & 6 \\
\hline Retinol $(\mu \mathrm{g})$ & 122 & 55 & 754 & 496 & 777 & 498 & 664 & 301 & 1251 & 968 & 1047 \\
\hline Carotene $(\mu g)$ & 45 & 20 & 432 & 705 & 229 & 2354 & 2295 & 1634 & 2787 & 2593 & 1923 \\
\hline
\end{tabular}

and vitamins $B_{6}$ and $B_{12}$ were supplied by supplements. In general, the contribution of supplements to mean nutrient intakes was higher in women than in men. The contribution of supplements to mean intakes of iron, copper, zinc, folate, thiamin, riboflavin, retinol and vitamins $B_{6}, C, E$ and $D$ was equal to or higher than that of food and at least a third of the mean intakes of magnesium, manganese, niacin and vitamin $B_{12}$ were provided by supplements.

In Table 5, the mean daily intakes of micronutrients at the 95th percentile in male and female supplement users are compared with the $\mathrm{UL}^{20-28}$. Values were calculated for food plus supplements and for food sources only. Women at the 95th percentile of iron intake from food plus supplements exceeded the UL of $45 \mathrm{mg}$ by over $65 \mathrm{mg}$. Mean iron intakes at the 95 th percentile from food sources in this group were almost $28 \mathrm{mg}$ lower than the UL. Mean vitamin $\mathrm{B}_{6}$ intakes at the 95 th percentile from food plus supplements were $41.4 \mathrm{mg}$, which exceeded the UL of $25 \mathrm{mg}$ by over $16 \mathrm{mg}$. The mean vitamin $\mathrm{B}_{6}$ intake at the 95th percentile in this group from food only was $3.1 \mathrm{mg}$. Mean intakes of pre-formed niacin at the 95th percentile in men and women exceeded the UL of $35 \mathrm{mg}$, when intakes from food plus supplements were considered, and in men from food sources only. In men, mean intakes of retinol at the 95th percentile approached the UL of $3000 \mu \mathrm{g}$ when supplements were included. No other UL for minerals or vitamins was exceeded at the 95th percentile of mean intakes.

\section{Discussion}

This report describes dietary supplement use in a representative sample of the Irish adult population with specific emphasis on evaluating the efficacy of supplements in promoting adequate micronutrient intakes and 
Table 5 Mean daily intakes of micronutrients at the 95th percentile in male and female supplement consumers in the North/South Ireland Food Consumption Survey compared with the tolerable upper intake levels (ULS)

\begin{tabular}{|c|c|c|c|c|c|c|c|}
\hline & \multirow[b]{2}{*}{ UL } & \multicolumn{3}{|c|}{ Food plus supplements } & \multicolumn{3}{|c|}{ Food only } \\
\hline & & $\begin{array}{c}\text { Total } \\
n=323\end{array}$ & $\begin{array}{c}\text { Men } \\
n=103\end{array}$ & $\begin{array}{l}\text { Women } \\
n=220\end{array}$ & $\begin{array}{c}\text { Total } \\
n=323\end{array}$ & $\begin{array}{c}\text { Men } \\
n=103\end{array}$ & $\begin{array}{l}\text { Women } \\
n=220\end{array}$ \\
\hline \multicolumn{8}{|l|}{ Minerals } \\
\hline Calcium (mg) & $2500^{*}$ & 1578 & 1653 & 1450 & 1433 & 1652 & 1255 \\
\hline Iron (mg) & $45 t$ & 84.6 & 30.4 & 110.4 & 19.7 & 25.9 & 17.2 \\
\hline Copper (mg) & $10 t$ & 3.4 & 4 & 3 & 2.7 & 3.2 & 2.1 \\
\hline Zinc $(\mathrm{mg})$ & $40 \dagger$ & 25.5 & 27.9 & 23.1 & 14.9 & 20 & 12 \\
\hline Magnesium (mg) & $\begin{array}{c}350^{*} \\
\text { (supplemental) }\end{array}$ & 555 & 600 & 428 & 484 & 581 & 385 \\
\hline Manganese (mg) & $11 t$ & 7.7 & 8.3 & 6.6 & 5.8 & 7.9 & 5.1 \\
\hline \multicolumn{8}{|l|}{ Vitamins } \\
\hline Vitamin C (mg) & $2000 \ddagger$ & 1036 & 1202 & 660 & 185 & 194 & 185 \\
\hline Folic acid $(\mu \mathrm{g})$ & $1000 \ddagger$ & 692 & 724 & 693 & 467 & 561 & 377 \\
\hline Thiamin $(\mathrm{mg})$ & None§ & 10.9 & 7.4 & 11.3 & 3.1 & 4 & 2.3 \\
\hline Riboflavin (mg) & None§ & 6.8 & 5.7 & 6.9 & 3.1 & 3.9 & 2.7 \\
\hline Pre-formed niacin (mg) & $35 \prod$ & 58.2 & 60 & 57.2 & 39.2 & 42 & 29.2 \\
\hline Vitamin $\mathrm{B}_{6}(\mathrm{mg})$ & $25 \S$ & 18.2 & 11.6 & 41.4 & 4.3 & 5.7 & 3.1 \\
\hline Vitamin $B_{12}(\mu \mathrm{g})$ & None§ & 16.7 & 21.4 & 16.1 & 9.7 & 14.4 & 7.6 \\
\hline Vitamin E (mg) & $1000 \ddagger$ & 133 & 273 & 72 & 11 & 11.9 & 10.7 \\
\hline Vitamin D ( $\mu \mathrm{g})$ & $50^{*}$ & 14.5 & 14 & 14.9 & 7.4 & 10.6 & 6.3 \\
\hline Retinol $(\mu \mathrm{g})$ & $3000 t$ & 2529 & 2974 & 2359 & 1691 & 2067 & 1135 \\
\hline Carotene $(\mu \mathrm{g})$ & None§ & 6334 & 5789 & 6582 & 6227 & 5788 & 6401 \\
\hline
\end{tabular}

assessing the risk of adverse effects to supplement users at the 95 th percentile of micronutrient intakes.

A recent report ${ }^{29}$ indicated that it might be necessary to use a combination of several approaches to gain an accurate assessment of supplement use. In the present study, $28 \%$ of respondents reported that they were currently using dietary supplements, and $23 \%$ of respondents recorded consuming a supplement during the week of data collection. All of the respondents who consumed a supplement during the recording week had reported in the questionnaire that they were currently taking supplements. A longer period of data collection may be necessary to gain an accurate record of the types and doses of supplements consumed by all supplement users. Other studies of habitual supplement use in the USA ${ }^{30}$, Germany $^{31}$, The Netherlands ${ }^{32}$ and Sweden ${ }^{33}$ have reported similar rates of consumption. In the UK, the Dietary and Nutritional Survey of British Adults ${ }^{34}$, published in 1990 , reported that $15 \%$ of the respondents were currently taking supplements. Preliminary results from the first 2000 participants in the EPIC study in Norfolk showed that $37.5 \%$ of respondents regularly consumed a supplement ${ }^{3}$, suggesting that the rate of supplement use in the UK is increasing. In the current survey, twice as many women used supplements as men. In addition, the prevalence of supplement use was slightly higher in the older age groups compared with the 18-35 year age category. These trends have been observed previously ${ }^{30,31,34}$.
The mean intakes of micronutrients were higher in supplement users than non-users when the contributions from supplements were included. When intakes in users from food sources only were compared with those of non-users, the values in men were similar. However, in women, the intakes of iron, magnesium, manganese, niacin and vitamins $\mathrm{C}$ and $\mathrm{E}$ were significantly higher in users (by 3 to $12 \%$ ) from food sources only than in nonusers. Results from a recent study ${ }^{4}$ showed that, before supplements were taken into account, supplement users had higher intakes than non-users of all micronutrients, apart from vitamin $B_{12}$. Another study in the USA ${ }^{30}$ showed that female supplement users had higher intakes of calcium and vitamins A, C and E from food sources than non-users. These observations appear to support the hypothesis that supplement users eat diets that are at least as nutritious as those of non-users, and may be unnecessarily consuming supplements to correct nutritional deficiencies ${ }^{4}$. While the adequacy of nutrient intakes was not evaluated in the above studies, the present study shows that the adequacy of intakes in female supplement users (from food sources only) was better for calcium, iron, copper, vitamin $C$, folate and vitamin $\mathrm{A}$, as indicated by the percentages who had mean daily nutrient intakes lower than the average requirements.

Mean intakes in supplement users and non-users in the present study were compared with estimated average requirements. The $A R$ is defined as the nutrient intake 
value that is estimated to meet the requirement, defined by a specified indicator of adequacy, in $50 \%$ of the individuals in a life-stage and gender group. At this level of intake, the remaining $50 \%$ of the specified group would not meet their nutrient needs. The percentage of persons with intakes that are lower than the AR is useful for assessing the prevalence of inadequate intakes within a group $^{20}$. Carriquiry has explained this concept clearly and in more detail in a recent paper ${ }^{35}$. In men, the percentage of users and non-users of supplements with micronutrient intakes (from food only) below the AR was generally below 10, except for calcium, zinc, riboflavin and vitamin A. In users, supplements had no effect on the adequacy of calcium intakes, but did reduce the percentages below the AR from 19 to 13 for zinc, from 14 to 6 for riboflavin and from 20 to 5 for vitamin $\mathrm{A}$.

Overall, the percentage of women who had mean nutrient intakes below the AR was higher than that of men and this was particularly evident with regard to minerals. In female users of supplements aged 18-50 years, the proportion with mean iron intakes below the AR $(10 \mathrm{mg})^{19}$ was $50 \%$ from food only, which was reduced to $25 \%$ when supplements were included. A much smaller percentage of women in the 51-64 year age group had mean iron intakes that were lower than the AR for nonmenstruating women $(6 \mathrm{mg})^{19}$. These data indicate that supplements containing iron make an important contribution to the diets of menstruating women, but they may be largely unnecessary in post-menopausal women, whose iron intakes reach adequate levels in most cases. The impact of supplement use on reducing the percentages of women whose mean intakes did not reach the AR for calcium (from 23 to 16), copper (from 20 to 15), zinc (from 15 to 12), riboflavin (from 23 to 14) and vitamin A (from 18 to 14) was smaller than the impact of supplements on iron intakes in menstruating women (from 50 to 25).

In the current study, the contribution of supplements to the mean daily intake of each nutrient was evaluated for supplement users who obtained that nutrient from a supplement. Although twice as many women as men used supplements, the percentage obtaining individual nutrients in supplemental form was similar for men and women (Tables $4 \mathrm{a}$ and $4 \mathrm{~b}$ ). Supplements provided a substantial proportion of the mean daily intake of individual nutrients among consumers of that nutrient in supplemental form. For example, supplements contributed more than food to the mean intakes of iron, zinc and folate in women, and of thiamin, riboflavin, retinol and vitamins $\mathrm{B}_{6}, \mathrm{C}, \mathrm{D}$ and $\mathrm{E}$ in men and women who obtained these nutrients in supplemental form. This observation highlights the importance of the careful recording of supplement use in studies that measure dietary intake to correctly classify respondents by intake.

In an accompanying paper ${ }^{36}$, data from the current study are presented which indicate that the recently published recommendation from $\mathrm{COMA}^{37}$, that total folate intake should be about $600 \mu \mathrm{g} \mathrm{day}{ }^{-1}$ in women of childbearing potential to reduce the risk of neural tube defects (NTD), was met only by a very small percentage of Irish women aged 18-50 years. The data show that in females aged 18-50 years who consumed supplemental folate ( $n=80$ out of 555 ), mean intakes of folate were $480 \mu \mathrm{g}(233 \mu \mathrm{g}$ from food and $248 \mu \mathrm{g}$ from supplements), indicating a reduced risk of NTD in this group. However, only $21(26 \%)$ of these women achieved a mean daily folate intake $\geq 600 \mu \mathrm{g}$. Of the women who did not take supplements, none had mean intakes that approached this level.

The criteria of adequacy for setting ARs do not take into account potential health benefits of higher intakes of some nutrients, e.g. vitamins $\mathrm{C}$ and $\mathrm{E}$, which may have protective effects against certain ageing-related chronic diseases. Vitamin $\mathrm{E}$ acts as a physiological antioxidant that prevents the propagation of lipid peroxidation. Oxidation of low-density lipoproteins may be a key step in the development of coronary atherosclerosis. Epidemiological evidence indicates a protective effect of dietary vitamin $\mathrm{E}$ against cardiovascular disease and some authors ${ }^{38,39}$ believe that the evidence is already convincing enough to recommend intakes of at least $87 \mathrm{mg}$ day $^{-1}$. However, the four large-scale intervention studies published to date do not provide sufficient data to confirm a protective effect of vitamin $\mathrm{E}$ against heart disease $^{22}$. The attainment of vitamin $\mathrm{E}$ intakes of $87 \mathrm{mg}$ day ${ }^{-1}$ is not feasible in the population without the use of supplements. In men who consumed supplemental vitamin $\mathrm{E}$ ( $n=80$ out of 662 ), the total mean daily intake of vitamin $\mathrm{E}$ was $44.5 \mathrm{mg}$. Only eight of these men achieved mean intakes that exceeded $87 \mathrm{mg} \mathrm{day}^{-1}$.

In the current study, the mean daily micronutrient intakes of supplement users at the 95th percentile from food and supplements were compared with tolerable upper intake levels (ULs) ${ }^{20-28}$. Mean intakes of micronutrients at the 95th percentile exceeded the UL for pre-formed niacin, vitamin $\mathrm{B}_{6}$ and iron (in women only). While there were no female non-users of supplements who exceeded the UL for iron, 21 out of the 96 women who consumed supplemental iron exceeded the $\mathrm{UL}^{21}$ of $45 \mathrm{mg}$. Gastrointestinal side effects were selected as the critical adverse effects on which to base the UL for iron ${ }^{21}$. Apart from the well-documented Bantu haemosiderosis, there are only a few case reports on prolonged iron therapy and iron overload. Calculations in fertile women of the expected body iron burden at different doses of iron taken over periods of up to 15 years have concluded that $60 \mathrm{mg}$ iron daily over 5 years might lead to body iron stores that are close to the cut-off values for serum ferritin in iron overload, but would not result in iron overload ${ }^{40}$. It should be noted that in the current users of supplemental iron who exceeded the UL, most of the iron supplements used were prescribed for iron deficiency 
anaemia. In addition, estimations of $\mathrm{Fe}$ intake were carried out over a 7-day period and may not represent chronic iron supplement use in these particular women.

The $\mathrm{UL}^{25}$ for vitamin $\mathrm{B}_{6}$ of $25 \mathrm{mg}$ was exceeded by one man and by 14 of the 94 women who consumed this vitamin in supplemental form. Exceeding the UL of $25 \mathrm{mg}$ was associated with the consumption of supplements that contained 25 to $50 \mathrm{mg}$ of vitamin $\mathrm{B}_{6}$, as opposed to multivitamin preparations which usually contain quantities of $\mathrm{B}_{6}$ that are similar to the recommended dietary allowances of $15 \mu \mathrm{g} \mathrm{B}_{6}$ per $\mathrm{g}$ protein. A chronic mean daily intake of $25 \mathrm{mg} \mathrm{B}_{6}$ has not been associated with any adverse effects in any published studies. However, minor neurological symptoms may be apparent at doses of $100 \mathrm{mg} \mathrm{day}^{-1}$ over a prolonged period ${ }^{25}$. These symptoms are reversible on cessation of supplementation.

The $\mathrm{UL}^{28}$ for niacin of $35 \mathrm{mg}$ was exceeded at the 95th percentile from food plus supplements in men and women. In total, 44 out of 51 male and 41 out of 94 female users of supplemental niacin exceeded the UL. The maximum daily intake of pre-formed niacin from the sum of food sources and supplements was $91.5 \mathrm{mg}$ and from supplements was $66.6 \mathrm{mg}$. The critical adverse effect for this UL is flushing, which is a transient effect resulting in a reddened flush primarily on the face, arms and chest $^{28}$. There is no evidence of adverse effects from the consumption of naturally occurring niacin in foods, and the UL has been set based on evidence of flushing from the intake of nicotinic acid as a supplement, food fortificant or pharmacological agent ${ }^{28}$. Supplemental nicotinic acid provided about one-third of the mean daily intake of niacin at the 95th percentile of niacin intakes. Over $40 \%$ of pre-formed niacin from food sources came from meat, meat products and fish ${ }^{28}$, in which it is present mainly in the form of nicotinamide ${ }^{41}$, which is not associated with flushing ${ }^{28}$. Thus, although it was not possible to quantify the proportions of nicotinamide and nicotinic acid consumed in food, the estimates of those who exceeded the UL for pre-formed niacin appear to considerably overestimate the risk of exposure to excess nicotinic acid. Mean niacin intakes from food sources only exceeded the UL in a small number of men but this included a substantial contribution of nicotinamide from meat, indicating that the risk of adverse effects from intake of nicotinic acid in foods is low.

\section{Conclusions}

This study found that nutritional supplements are regularly used by $23 \%$ of the Irish adult population. Twice as many women as men are supplement users. Mean intakes of micronutrients were higher in supplement users than non-users when the contribution from supplements was included. Female supplement users had slightly higher mean intakes of some micronutrients from food sources compared with non-users. Supplementation appears to be beneficial in promoting adequate intakes of some micronutrients, particularly iron and folate in women aged $18-50$ years and vitamin A in men. Among consumers of specific nutrients in supplemental form, supplements provided a substantial proportion of the mean daily intakes of those nutrients. Although the consumption of folate supplements increased total folate intake by an average of two-fold in consumers, the recommendation that folate intakes should be $600 \mu \mathrm{g}$ in women of childbearing potential for the prevention of NTD was only met by $26 \%$ of women aged 18 to 50 years who consumed supplemental folate (and by none who did not). Twenty-two per cent of women who consumed supplemental iron exceeded the UL for iron, and 15\% of women who consumed supplemental vitamin $\mathrm{B}_{6}$ exceeded the UL for $\mathrm{B}_{6}$. A high proportion of male and female consumers of supplemental niacin exceeded the UL for niacin. However, since the estimate of niacin intake includes a substantial contribution from nicotinamide, which is not associated with flushing, the number of people with intakes of pre-formed niacin above the UL appears to considerably overestimate the risk of exposure to excess nicotinic acid. The risk of adverse effects from exposure to nicotinic acid in foods is low. Other than these findings for iron, vitamin $\mathrm{B}_{6}$ and niacin, there was little risk of exceeding the UL for other micronutrients among users of nutritional supplements.

\section{References}

1 Food Safety Advisory Committee. Food Supplements and Health Foods. Report to the Minister for Health and the Minister for Agriculture, Food and Forestry. Dublin: Food Safety Advisory Committee, 1994.

2 Nesheim MC. What is the research base for the use of dietary supplements? Public Health Nutr. 1999; 2: 35-8.

3 Welch AA, Mulligan AA, Luben RN, Bingham SA. Intake of selected nutrients from vitamin and mineral supplements by subjects in the EPIC study, Norfolk, UK. Proc. Nutr. Soc. 1998; 57: 154A.

4 Kirk SFL, Cade JE, Barrett JH, Conner M. Diet and lifestyle characteristics associated with dietary supplement use in women. Public Health Nutr. 1999; 2: 69-73.

5 Hathcock JN. Vitamins and minerals: efficacy and safety. Am. J. Clin. Nutr. 1997; 66: 427-37.

6 Harrington KE, Robson PJ, Kiely M, Livingstone MBE, Lambe J, Gibney MJ. The North/South Ireland Food Consumption Survey: survey design and methodology. Public Health Nutr. 2001; 4(5A): 1037-42.

7 Kiely M, Harrington KE, Robson PJ, Flynn A, Cran G. Sampling description and procedures used to conduct the North/South Ireland Food Consumption Survey. Public Health Nutr. 2001; 4(5A): 1029-35.

8 Holland B, Welch AA, Unwin ID, Buss DH, Paul AA, Southgate DAT. McCance $\&$ Widdowson's The Composition of Foods, 5th ed. Royal Society of Chemistry and Ministry of Agriculture, Fisheries and Food. London: HMSO, 1995.

9 Holland B, Unwin ID, Buss DH. Cereals and Cereal Products. Third Supplement to McCance \& Widdowson's The Composition of Foods, 4th ed. Royal Society of Chemistry and Ministry of Agriculture, Fisheries and Food. London: HMSO, 1988. 
10 Holland B, Unwin ID, Buss DH. Milk Products and Eggs. Fourth Supplement to McCance \& Widdowson's The Composition of Foods, 4th ed. Royal Society of Chemistry and Ministry of Agriculture, Fisheries and Food. London: HMSO, 1989.

11 Holland B, Unwin ID, Buss DH. Vegetables, Herbs and Spices. Fifth Supplement to McCance \& Widdowson's The Composition of Foods, 4th ed. Royal Society of Chemistry and Ministry of Agriculture, Fisheries and Food. London: HMSO, 1991

12 Holland B, Unwin ID, Buss DH. Fruit and Nuts. First Supplement to McCance $\&$ Widdowson's The Composition of Foods, 5th ed. Royal Society of Chemistry and Ministry of Agriculture, Fisheries and Food. London: HMSO, 1992.

13 Holland B, Welch AA, Buss DH. Vegetable Dishes. Second Supplement to McCance $\&$ Widdowson's The Composition of Foods, 5th ed. Royal Society of Chemistry and Ministry of Agriculture, Fisheries and Food. London: HMSO, 1996.

14 Holland B, Brown J, Buss DH. Fish and Fish Products. Third Supplement to McCance E Widdowson's The Composition of Foods, 5th ed. Royal Society of Chemistry and Ministry of Agriculture, Fisheries and Food. London: HMSO, 1993.

15 Chan W, Brown J, Buss DH. Miscellaneous Foods. Supplement to McCance \& Widdowson's The Composition of Foods. Royal Society of Chemistry and Ministry of Agriculture, Fisheries and Food. London: HMSO, 1994.

16 Chan W, Brown J, Lee SM, Buss DH. Meat, Poultry and Game. Supplement to McCance \& Widdowson's The Composition of Foods. Royal Society of Chemistry and Ministry of Agriculture, Fisheries and Food. London: HMSO, 1995.

17 Chan W, Brown J, Church SM, Buss DH. Meat Products and Dishes. Supplement to McCance $\mathcal{E}$ Widdowson's The Composition of Foods. Royal Society of Chemistry and Ministry of Agriculture, Fisheries and Food. London: HMSO, 1996.

18 Patterson RE, Kristal AR, Levy L, McLerran D, While E. Validity of methods used to assess vitamin and mineral supplement use. Am. J. Epidemiol. 1998; 148: 643-9.

19 Scientific Committee for Food. Nutrient and Energy Intakes for the European Community. Luxembourg: Office for Official Publications of the European Communities, 1993.

20 Food and Nutrition Board, Institute of Medicine. Dietary Reference Intakes for Calcium, Phosphorous, Magnesium, Vitamin $D$ and Fluoride. Washington, DC: National Academy Press, 1997.

21 Food and Nutrition Board, Institute of Medicine. Dietary Reference Intakes for Vitamin A, Vitamin K, Arsenic, Boron, Chromium, Copper, Iodine, Iron, Manganese, Molybdenum, Nickel, Silicon, Vanadium and Zinc. Washington, DC: National Academy Press, 2001 [prepublication copy].

22 Food and Nutrition Board, Institute of Medicine. Dietary Reference Intakes for Vitamin C, Vitamin E, Selenium and Carotenoids. Washington, DC: National Academy Press, 2000.

23 Scientific Committee for Food. Opinion of the Scientific Committee for Food on the Tolerable Upper Intake Level of Folate [Online]. Available at http://www.europa.eu.int. 19 October 2000

24 Scientific Committee for Food. Opinion of the Scientific Committee for Food on the Tolerable Upper Intake Level of
Vitamin $B_{2}$ [Online]. Available at http://www.europa.eu.int. 22 November 2000

25 Scientific Committee for Food. Opinion of the Scientific Committee for Food on the Tolerable Upper Intake Level of Vitamin $B_{6}$ [Online]. Available at http://www.europa.eu.int. 19 October 2000.

26 Scientific Committee for Food. Opinion of the Scientific Committee for Food on the Tolerable Upper Intake Level of Vitamin $B_{12}$ [Online]. Available at http://www.europa. eu.int. 19 October 2000

27 Scientific Committee for Food. Opinion of the Scientific Committee for Food (expressed) on the Tolerable Upper Intake Level of Carotene [Online]. Available at http:// www.europa.eu.int. 19 October 2000.

28 Food and Nutrition Board, Institute of Medicine. Dietary Reference Intakes for Thiamin, Riboflavin, Niacin, Vitamin $B_{6}$, Vitamin $B_{12}$, Pantotbenic Acid, Biotin and Choline. Washington, DC: National Academy Press, 1998.

29 Bates CJ, Prentice A, van der Pols JC, Walmsley C, Pentieva $\mathrm{KD}$, Finch S, Smithers G, Clarke PC. Estimation of the use of dietary supplements in the National Diet and Nutrition Survey: People aged 65 years and over. An observed paradox and a recommendation. Eur. J. Clin. Nutr. 1998; 52: $917-23$

30 Slesinski MJ, Subar AF, Kahle LL. Dietary intake of fat, fiber and other nutrients is related to the use of vitamin and mineral supplements in the United States: The 1992 National Health Interview Survey. J. Nutr. 1996; 126: 3001-8.

31 Schellhorn B, Doring A, Stieber J. Use of vitamin and mineral supplements: results from the survey $1994 / 5$ of the WHO MONICA Project Augsburg. Z. Ernaebrungsw. 1998; 37: 198-206.

32 Dorant E, Vandenbrandt PA, Hamstra AM, Feenstra MH, Goldbohm RA, Hermus RJJ, Sturmans F. The use of vitamins, minerals and other dietary supplements in the Netherlands. Int. J. Vitam. Nutr. Res. 1993; 63: 4-10.

33 Elmstahl S, Wallstrom P, Janzon L, Johansson U. The prevalence of anaemia and mineral supplement use in a Swedish middle-aged population. Results from the Malmo Diet and Cancer Study. Eur. J. Clin. Nutr. 1996; 50: 450-5.

34 Gregory J, Foster K, Tyler H, Wiseman M. The Dietary and Nutritional Survey of British Adults. London: HMSO, 1990.

35 Carriquiry AL. Assessing the prevalence of nutrient inadequacy. Public Health Nutr. 1999; 2: 23-33.

36 O'Brien MM, Kiely M, Harrington KE, Robson PJ, Strain JJ, Flynn A. The North/South Ireland Food Consumption Survey: vitamin intakes in 18-64-year-old adults. Public Health Nutr. 2001; 4(5A): 1069-79.

37 Department of Health. Folic Acid and the Prevention of Disease. Report of the Committee on Medical Aspects of Food and Nutrition Policy. London: HMSO, 2000.

38 Weber $\mathrm{P}$, Bendich A, Machlin LJ. Vitamin E and human health: rationale for determining recommended intake levels. Nutrition 1997; 13: 450-60.

39 Morrissey PA, Sheehy PJA. Optimal nutrition: vitamin E. Proc. Nutr. Soc. 1999; 58: 459-68.

40 Nordic Council of Ministers. Risk Evaluation of Essential Trace Elements - Essential versus Toxic Levels of Intake. Copenhagen: Nordic Council of Ministers, 1995.

41 Groff JL, Gropper SS, Hunt SM. Advanced Nutrition and Human Metabolism, 2nd ed. St Paul, MN: West Publishing Company, 1995. 